\title{
Definition, Classification and Diagnosis of Diabetes Mellitus
}

Authors

Affiliations
W. Kerner ${ }^{1}$, J. Brückel ${ }^{2}$

Klinik für Diabetes und Stoffwechselkrankheiten, Klinikum Karlsburg

Abteilung Innere Medizin, Oberschwaben Klinik, Krankenhaus Wangen
Last update

$3 / 2014$

\section{Bibliography}

DOI http://dx.doi.org/ 10.1055/s-0034-1366278 Exp Clin Endocrinol Diabetes 2014; 122: 384-386 ( ) J. A. Barth Verlag in Georg Thieme Verlag KG Stuttgart · New York . ISSN 0947-7349

Correspondence

Prof. Dr. med. Wolfgang Kerner

Klinikum Karlsburg Klinik für Diabetes und Stoffwechselkrankheiten Greifswalder Str. 11 17495 Karlsburg Tel.: $038355 / 701397$

Fax: $038355 / 701582$

kerner@drguth.de

\section{Definition}

$\nabla$

Diabetes mellitus is a general term for heterogeneous disturbances of metabolism for which the main finding is chronic hyperglycaemia. The cause is either impaired insulin secretion or impaired insulin action or both.

\section{Classification}

$\nabla$

Type 1 Diabetes

- $\beta$-cell destruction which leads to absolute insulin deficiency

- Usually mediated by immune mechanisms

- LADA (latent autoimmune diabetes in adults) is classified as type 1 diabetes.

Type 2 Diabetes

- Can range from predominant insulin resistance with relative insulin deficiency to prevailing defective secretion with insulin resistance.

- Is frequently associated with other problems of the so-called metabolic syndrome

\section{Other Specific Diabetes Types}

- Diseases of the exocrine pancreas (e.g. pancreatitis, cystic fibrosis, hemochromatosis)

- Endocrinopathies (e.g. Cushing syndrome, acromegaly, pheochromocytoma)

- Drug induced (e.g. glucocorticoids, neuroleptics, alpha-interferons, pentamidine)

- Genetic defects of the $\beta$-cell function (e.g. MODY forms)

- Genetic defects of insulin action

- Other genetic syndromes which can be associated with diabetes

- Infections

- Rare forms of auto-immune mediated diabetes

\section{Gestational Diabetes \\ $\nabla$}

Glucose tolerance impairments that first appear or are first diagnosed during pregnancy.

\section{Diagnostic Criteria \\ V}

Important

Only standardised, quality assured laboratory methods may be applied when venous plasma glucose and HbA1c are measured. The current gold standard for diagnosing diabetes is measurement of glucose in venous plasma. This measurement can be accurate only if glycolysis is inhibited in the blood sample as soon as the sample is drawn. This can be done in two ways. Either the blood tube is stored on ice and the blood is centrifuged within 30 minutes, or glycolysis in the tube is effectively inhibited by appropriate additives (citrate plus fluoride; fluoride by itself is not sufficient). The glucose levels stated in the practice guidelines apply to venous plasma. (These levels correspond to the recommendations of the Deutsche Gesellschaft für Klinische Chemie und Laboratoriumsmedizin (DGKL) and the Deutsche Diabetes Gesellschaft (DDG)).

\section{Diabetes Mellitus}

- $\mathrm{HbA} 1 \mathrm{c} \geq 6.5 \%$ ( $\geq 48 \mathrm{mmol} / \mathrm{mol})$

- Random plasma glucose $\geq 200 \mathrm{mg} / \mathrm{dl}$ $(\geq 11.1 \mathrm{mmol} / \mathrm{l})$

- Fasting plasma glucose $\geq 126 \mathrm{mg} / \mathrm{dl}$ $(\geq 7.0 \mathrm{mmol} / \mathrm{dl})$

- OGTT 2-hour glucose in venous plasma $\geq 200 \mathrm{mg} / \mathrm{dl}(\geq 11.1 \mathrm{mmol} / \mathrm{l})$

These guidelines have been recommending the use of HbA1c for diagnosing diabetes since 2010. This became possible through international standardisation of the measurement method. On the other hand, epidemiological investigations in recent years have shown that the specificity of HbA1c 
$\geq 6.5 \%$ is high enough to justify a diagnosis of diabetes and the sensitivity of HbA1c $<5.7 \%$ is high enough to justify exclusion of a diagnosis of diabetes. For these reasons, HbA1c is suitable as a primary diagnostic tool for excluding diabetes with great certainty and for making a diagnosis of diabetes in some cases. When the HbA1c level lies between 5.7 and 6.4\%, these guidelines recommend that diabetes and prediabetes be diagnosed by measuring glucose in accordance with traditional criteria. See $\bullet$ Fig. 1, 2 in the annex for the recommended diagnostic approach. The HbA1c level cannot be applied to making a diagnosis if an inaccurate HbA1c level is to be expected due to any of the factors stated in - Table 2.

See Table 4 for details on OGTT and $\bullet$ Table 1 for differential diagnostic criteria for type 1 and type 2 diabetes.

\section{Impaired Fasting Glucose}

IFG for fasting glucose levels from $100-125 \mathrm{mg} / \mathrm{dl}$ (5.6 mmol$6.9 \mathrm{mmol} / \mathrm{l}$ ) in venous plasma.

\section{Impaired Glucose Tolerance}

IGT for 2-hour plasma glucose in the OGIT in the range of $140-199 \mathrm{mg} / \mathrm{dl}(7.8-11.0 \mathrm{mmol} / \mathrm{l})$ with fasting glucose < $126 \mathrm{mg} /$ $\mathrm{dl}(<7.0 \mathrm{mmol} / \mathrm{l})$.

\section{Gestational Diabetes}

The OGTT diagnostic criteria given in 0 Table 3 are based on the recently published results of the HAPO study. The differences to the previous borderline values are small, but but now gestational diabetes is indicated if any one (rather than at least two) of these values is exceeded.

\section{Annex}

Table 1 Differential Diagnostic Criteria for Type 1 and Type 2 Diabetes.

\begin{tabular}{|c|c|c|}
\hline & Type 1 Diabetes* & Type 2 Diabetes \\
\hline Manifestation age & Mostly children, adolescents and young adults & Mostly middle and old age \\
\hline Onset & Acute to subacute & Usually gradual \\
\hline Symptoms & Frequently polyuria, polydipsia, weight loss, fatigue & Frequently no complaints \\
\hline Body weight & Usually normal & Usually overweight \\
\hline Predisposition to ketosis & Pronounced & None or only slight \\
\hline Insulin secretion & Reduced or none & Below normal to high, qualitatively always impaired \\
\hline Insulin resistance & None (or only low) & Often pronounced \\
\hline Frequency in patient's family history & Usually negative & Typically positive \\
\hline Concordance with identical twins & 30 to $50 \%$ & Over $50 \%$ \\
\hline Heredity & Multifactorial (polygenetic) & $\begin{array}{l}\text { Multifactorial (most likely polygenetic, but genetic } \\
\text { heterogeneity is possible) }\end{array}$ \\
\hline $\begin{array}{l}\text { Associated with HLA (leukocyte antigen) } \\
\text { system }\end{array}$ & Present & Not present \\
\hline Antibodies associated with diabetes & Approx. $90-95 \%$ at onset (GAD, ICA, IA-2, IAA) & None \\
\hline Metabolism & Unstable & Stable \\
\hline $\begin{array}{l}\text { Response to insulin secretion stimulating } \\
\text { antidiabetics }\end{array}$ & Usually none & Usually good at first \\
\hline Insulin therapy & Required & $\begin{array}{l}\text { Usually not required until insulin secretion has } \\
\text { decreased after years of disease }\end{array}$ \\
\hline
\end{tabular}

* The LADA (latent autoimmune diabetes of adults) is associated with slower loss of beta cell function. Rapid failure of oral antidiabetics is to be expected. Analysis of GAD antibodies is recommended for cases of suspicion of LADA.

1. Haemoglobin variants ( $\mathrm{HbS}, \mathrm{HbE}, \mathrm{HbF}, \mathrm{HbC}, \mathrm{HbD}$ and others) the extent of the distortion depends on the method to determine HbA1c

2. Conditions with increased or decreased lifetime of the erythrocytes (haemolytic anaemia, iron deficiency anaemia, blood formation in the context of anaemia treatment, liver disease, kidney disease)

3. Chemical modifications of haemoglobin uraemia (carbamylated $\mathrm{Hb}$ ), high dosage long-time therapy with acetylsalicylic acid (acetylated $\mathrm{Hb}$ )

4. Inhibition of glycation (e. g. long-time therapy with ascorbic acid or vitamin E) the clinical significance of this phenomenon has not been studied well

5. Pregnancy
Table 2 Conditions which can lead to an inaccurate measurement of the HbA1c level.

$\begin{array}{ll}\text { Venous plasma } & \\ \mathbf{m g} / \mathbf{d l} & \mathbf{m m o l} / \mathbf{l} \\ \geq 92 & \geq 5.1 \\ \geq 180 & \geq 10.0 \\ \geq 153 & \geq 8.5\end{array}$

Table 3 Diagnosis of Gestational Diabetes. Diabetes is present if one or more of the criteria in the table are fulfilled. 


\section{Procedure for the $75 \mathrm{~g}$ OGTT pursuant to $\mathrm{WHO}$ guidelines}

Test must be performed in the morning

- after 10 - 16 hours abstention from nutrients (and alcohol)

- after at least 3 days of a diet rich in carbohydrates ( $\geq 150 \mathrm{~g}$ carbohydrates per day)

- while sitting or lying down (no muscular effort), no smoking before or during the test

At time 0 drink $75 \mathrm{~g}$ glucose (or equivalent quantity of hydrolysed starch) dissolved in $250-300 \mathrm{ml}$ water within

5 minutes.

- children $1.75 \mathrm{~g} / \mathrm{kg}$ body weight (at most $75 \mathrm{~g}$ )

- take blood samples at times 0 and 120 minutes.

- store and process the samples properly.

Test is contraindicated in case of a previous diagnosis of diabetes mellitus, gastric or intestinal resection, any gastrointestinal disease with changed resorption, or any intercurrent disease.
Table 4 Oral Glucose Tolerance Test (OGTT).

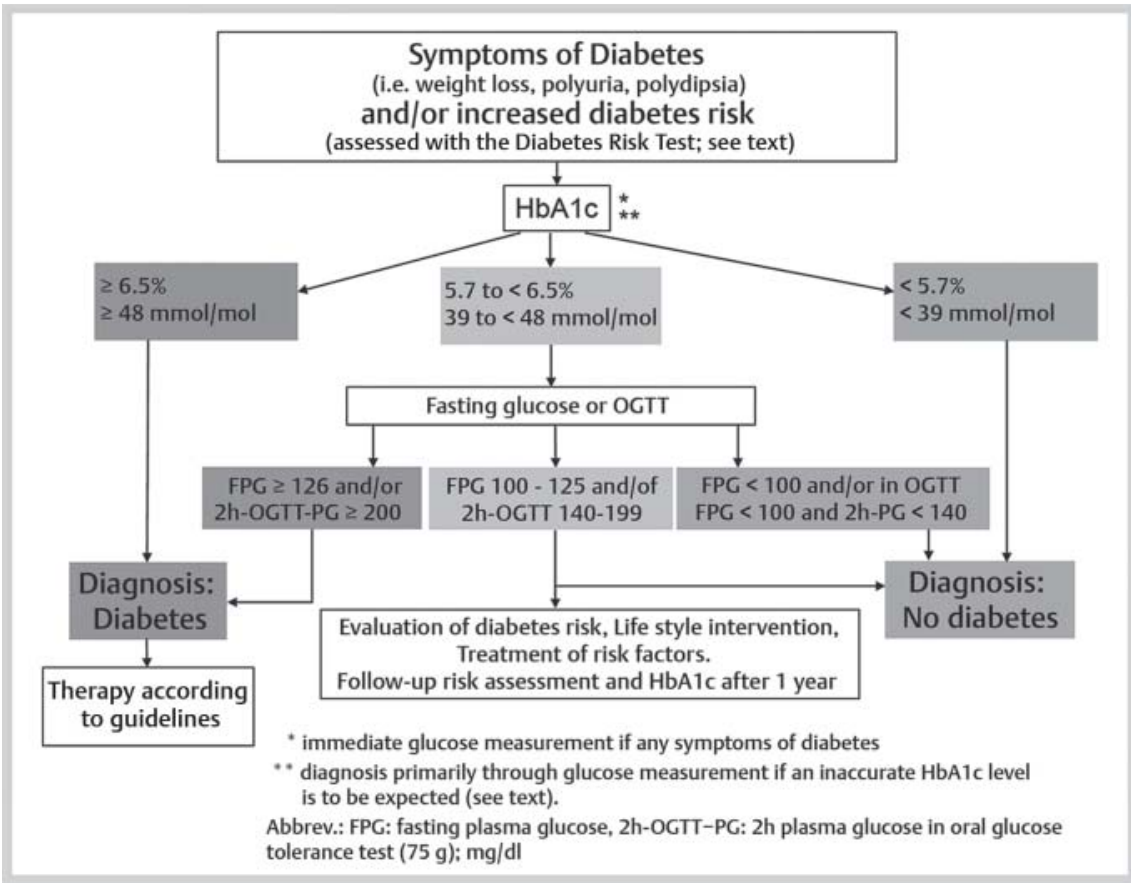

Fig. 1 Diagnostic Flowchart (glucose mg/dl).

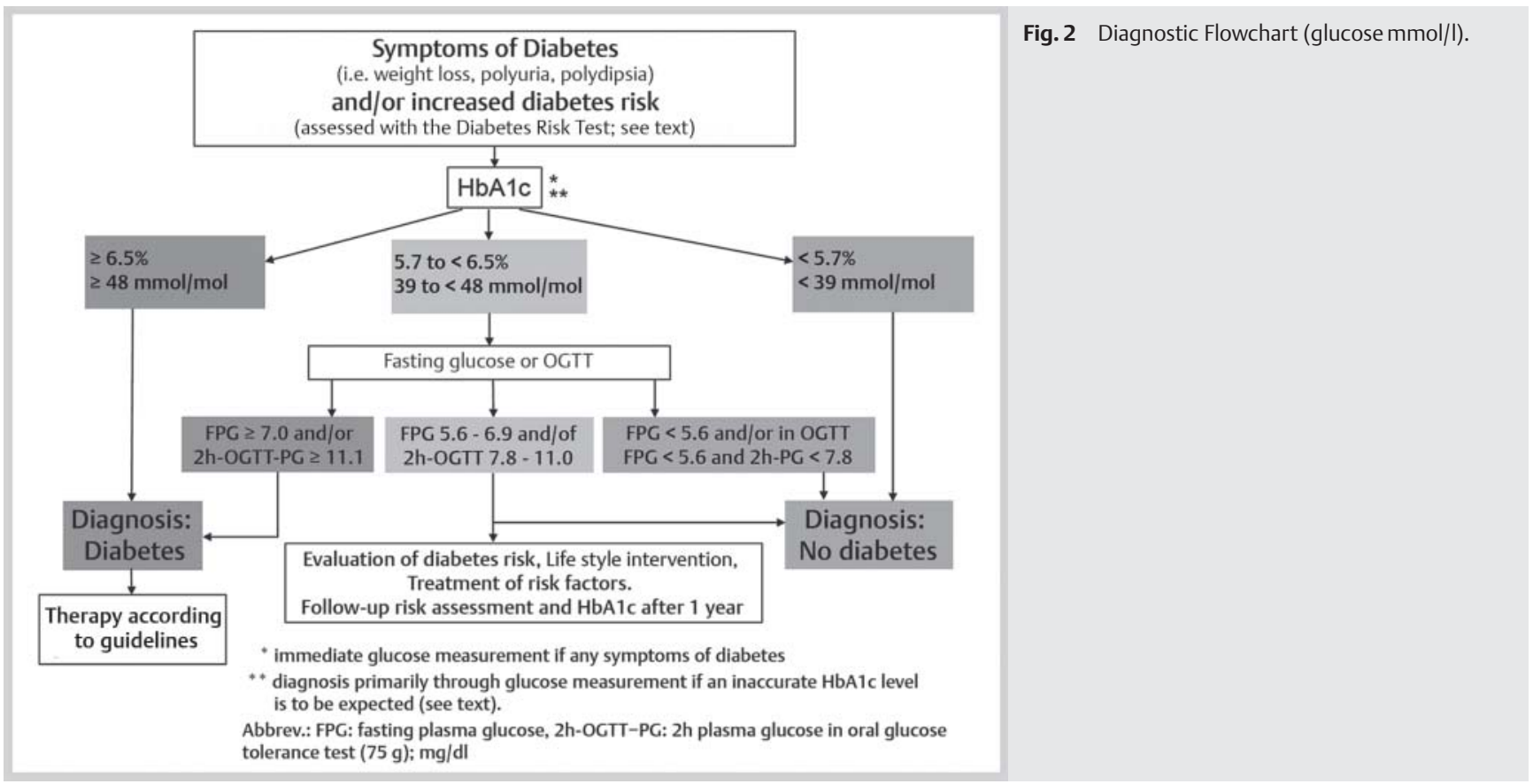

